\title{
Las Alegaciones Fiscales del Tribunal de la Inquisición de Mallorca ${ }^{1}$
}

\section{The Fiscal Allegations of the Court of the Spanish Inquisition in Majorca}

\author{
Rafael RAMIS BARCELÓ \\ Profesor de Historia del Derecho \\ Facultad de Derecho \\ Universitat de les Illes Balears \\ r.ramis@uib.es
}

Recibido: 10 de enero de 2011

Aceptado: 1 de marzo de 2011

\section{RESUMEN}

En este artículo se intentan clasificar las diferentes alegaciones fiscales concernientes al Tribunal de la Inquisición de Mallorca, conservadas en la subserie de legajos del Fondo del Consejo de la Inquisición del Archivo Histórico Nacional. El estudio de dichas alegaciones fiscales permite hacerse una idea de la actividad del Tribunal de la Inquisición en Mallorca durante los siglos XVIII y XIX (la época menos estudiada de la historia del Tribunal en la isla). Se destacan algunos rasgos comunes con las demás alegaciones fiscales procedentes del resto de los Tribunales de la Inquisición durante el mismo período y se examinan los casos singulares de Mallorca (el lulismo y los chuetas-xuetes-).

PALABRAS CLAVE: Tribunal de la Inquisición, Alegaciones Fiscales, Mallorca, Delitos contra la Fe.

\begin{abstract}
This paper tries to establish a classification of the Fiscal Allegations of the Court of the Spanish Inquisition in Majorca, that remain in the subset of files of the Collection of the Council of the Inquisition of the Archivo Histórico Nacional of Madrid. The study of the Fiscal Allegations gives an idea of the activity of the Court of the Inquisition in Mallorca during the $18^{\text {th }}$ and $19^{\text {th }}$ Centuries (the least studied period of the history of the Court in the island). Some common features with other fiscal allegations from the rest of the Courts of the Inquisition during the same period are underscored and some particular cases of Majorca are examined (mainly concerning Lullism and xuetes).
\end{abstract}

KEYWORDS: Inquisition Court, Fiscal Allegations, Majorca, Crimes against the Faith.

\section{RÉSUMÉ}

Cet article tente d'établir une classification des allégations fiscales du Tribunal de l'Inquisition espagnole à Majorque, qui restent dans le sous-ensemble des fichiers de la Collection du Conseil de l'Inquisition

\footnotetext{
${ }^{1}$ Agradezco al profesor Antonio Planas Rosselló la lectura del manuscrito y sus consejos, así como a la $\mathrm{D}^{\mathrm{ra}}$ Anna Serra la revisión técnica del escrito.
} 
de l'Archivo Histórico Nacional de Madrid. L'étude des allégations fiscales donne une idée de l'activité du Tribunal de l'Inquisition à Majorque pendant les XVIII e et XIX ${ }^{\mathrm{e}}$ siècles (la période la moins étudiée de l'histoire de la Cour dans l'île). Certaines caractéristiques communes avec les autres allégations fiscales du reste des tribunaux de l'Inquisition au cours de la même période sont soulignées et quelques cas particuliers de Majorque sont examinés (concernant principalement le lullisme et les xuetes).

MOTS-CLÉS : Tribunal de l’Inquisition, allégations fiscales, Majorque, Crimes contre la foi.

\section{ZUSAMMENFASSUNG}

Es werden nachfolgend die unterschiedlichen Schriftsätze der Staatsanwaltschaft hinsichtlich des Inquisitionsgerichtes von Mallorca aufgeschlüsselt, welche in der Akten-Unterserie des Fundus des Inquisitionsrates des Historischen Nationalarchives ruhen. Hieraus können Schlussfolgerungen für die Arbeit dieses Gerichtes vom 18. bis ins 19. Jahrhundert gezogen werden, was der am wenigsten erforschten Epoche der Gerichtsgeschichte der Insel entspricht. Einige gemeinsame Wurzeln mit den übrigen staatsanwaltschaftlichen Schriftsätzen anderer Inquisitionsgerichte schälen sich hinsichtlich derselben Epoche heraus. Indes werden auch Einzelfälle Mallorcas (Lulismo und xuetes) herausgestellt.

SCHLÜSSELWÖRTER: Inquisitionsgericht, staatsanwaltschaftliche Schriftsätze, Mallorca, Delikte gegen die Religion.

SUMARIO: 1 . Clasificación formal. 2. Clasificación material. 2.1. Causas de fe. 2.2. Pleitos y problemas de competencias. 2.3. Informaciones genealógicas. 3. Conclusiones.

Una subserie de legajos del Fondo del Consejo de la Inquisición del Archivo Histórico Nacional reúne los expedientes conservados concernientes a las alegaciones fiscales del Tribunal de la Inquisición de Mallorca ${ }^{2}$. Se trata de unos ochenta expedientes que pertenecen a los siglos XVIII y XIX, es decir, a la última etapa de la vida del Tribunal, que ha sido muy bien estudiado en su primera época ${ }^{3}$, pero que ha recibido menos atención en los dos últimos siglos de su actividad. Puesto que la Inquisición dieciochista y decimonónica en Mallorca es todavía poco conocida, tal vez la descripción y clasificación de esta subserie pueda ayudar a trabajos ulteriores sobre el tema.

En este artículo se pretende no tanto describir los contenidos cuanto establecer una clasificación de las diferentes alegaciones, que informan de manera clara de los asuntos más importantes que trataba la Inquisición en aquellos momentos. Resulta evidente que se han extraviado o estropeado varias alegaciones más, pero las que aquí se describen son altamente significativas de la orientación del Tribunal durante

\footnotetext{
${ }^{2}$ N. Moreno Garbayo, Catálogo de Alegaciones Fiscales, Madrid, Dirección General del Patrimonio Artístico y Cultural, 1977, pp. 161-169.

${ }^{3}$ Véase L. Pérez Martínez, L. Muntaner Mariano y M. Colom Palmer, El Tribunal de la Inquisición en Mallorca, 1578-1806, I, Mallorca, Miquel Font, 1986. Desafortunadamente, el segundo tomo nunca llegó a publicarse. También M. Colom Palmer, La Inquisició a Mallorca (1488-1578), Barcelona, Curial, 1992.
} 
la época borbónica, y ayudan a completar un mapa del derecho penal histórico en Mallorca, sobre todo en relación a los demás tribunales de la Monarquía Hispánica ${ }^{4}$.

\section{Clasificación formal}

Como es sabido, las alegaciones fiscales extractaban los expedientes originales remitidos por los diversos tribunales al Consejo de la Inquisición. Trataban sobre temas variados, aunque el peso mayor lo tenían las causas de fe. Toda esta documentación que enviaban los diferentes tribunales pasaba al relator, que redactaba el extracto (la alegación fiscal) y, con ello, el Consejo tomaba una decisión que era enviada de nuevo al tribunal correspondiente. Se le devolvía toda la documentación original de los expedientes y el Consejo sólo guardaba la alegación fiscal ${ }^{5}$.

Las alegaciones fiscales se caracterizaban por su carácter eminentemente sintético, que resumía los hechos más importantes y las calificaciones. En muchos casos la alegación tenía la extensión de una o dos caras de folio, aunque en los casos más complicados podía llegar a ocupar diez o más caras.

La fecha de formación de esta subserie de alegaciones del Tribunal de la Inquisición de Mallorca acota el período estudiado a la época que va desde la segunda mitad del XVIII hasta el año 1817. Se conservan un total de once legajos, que tienen desde un expediente hasta varios. Los más relevantes son el legajo 3.721, que abarca los expedientes $163,186-190$ y $201^{6}$; el legajo 3.723 que alberga los expedientes 86,96 109 y 145; el legajo 1.725, que contiene los expedientes 94-105; el legajo 3.727, que conserva los expedientes 113-125; y el legajo 3.732, que aloja los expedientes 236267, 415 y 463. Menos importantes son el legajo 3.720, que sólo alberga el expediente 14; el 3.722, que contiene el 311; el 3.735, que contiene el 403; el 3.736, que alberga los expedientes 123 y 124; y el legajo 3.740, que contiene el expediente 64 .

Se conservan algunas alegaciones cuya datación es difícil de determinar y sólo hay cuatro alegaciones fiscales anteriores a 1750 . Desde entonces, parece ser que se guardan todas las existentes, arrojando una media de seis alegaciones en cada década, salvo en la primera (1750-1759) y en las últimas (1800-1817) donde se concentran más procesos. De hecho, de 1723 a 1749 hay cuatro alegaciones, de 1750 a 1759 hay trece (se trata de la época con mayor actividad), de 1760 a 1769 hay ocho, de 1770 a 1779 hay seis, de 1780 a 1789 hay cinco, de 1790 a 1799 hay siete, de 1800 a 1809 hay nueve, y de 1810 a 1817 hay doce, de las cuales hay diez que se corresponden a 1814, año de restablecimiento del Tribunal. Hay también seis alegaciones del XVIII cuya datación no es exacta, y lo mismo ocurre con cuatro del XIX.

\footnotetext{
${ }^{4}$ Véase, en un sentido general, A. Planas Rosselló, El Derecho penal histórico de Mallorca (siglos XIIIXVIII) Palma, Universitat de les Illes Balears, 2001.

${ }^{5}$ N. Moreno Garbayo, Catálogo de Alegaciones Fiscales, cit. p. 8.

${ }^{6}$ No se ha podido consultar el expediente 188 de este legajo.
} 
La mayoría de las alegaciones de esta subserie pertenecen al Tribunal de la Inquisición de Mallorca, si bien hay unas pocas de mallorquines que son juzgados en otros tribunales inquisitoriales (un caso en Sevilla ${ }^{7}$, otro en Murcia $^{8}$, dos en Llerena ${ }^{9}$, cuatro en Zaragoza ${ }^{10}$, uno en la Corte $^{11}$ ) y un caso de una alegación fiscal de un proceso seguido en Valencia, por causas en Mallorca y Zaragoza ${ }^{12}$, que no van a examinarse en este artículo por no pertenecer a la jurisdicción del Tribunal de la Inquisición de Mallorca.

\section{Clasificación material}

La clasificación de las alegaciones fiscales según su contenido material suele hacerse, siguiendo el catálogo de Natividad Moreno, en cuatro grupos: causas de fe, pleitos civiles y de competencias, calificación y censura, y, por último, información genealógica $^{13}$. De ellos, el más abundante, con diferencia, es el de las causas de fe, mientras que los demás, frente a éste, representan un número casi marginal.

Este criterio de división, pese a ser archivístico y no histórico-jurídico, es útil para la historia del derecho, puesto que se trata de un instrumento del proceso y no plantea problemas serios sobre la naturaleza y competencias del Tribunal de la Inquisición. En este sentido, cabe decir que las alegaciones fiscales, al ser un resumen del proceso, pueden estudiarse sin mayores problemas atendiendo a estos criterios archivísticos que deberán revisarse, en su momento, al estudiar cada uno de los delitos ${ }^{14}$.

\subsection{Causas de fe}

Se han contado un total de setenta y cinco causas de esta índole, la mayoría de las cuales se sustanciaron en Mallorca. Sólo las nueve antes apuntadas, en las que había conexión con la Inquisición mallorquina se sustanciaron en otros tribunales, cuyas sedes ya se han indicado. Los delitos más comunes fueron los de proposiciones heréticas, solicitación, supersticiones, blasfemias y retención de libros prohibidos. Frente a los otros tribunales de la Monarquía Hispánica, y siguiendo el tenor de las alegaciones fiscales, el de Mallorca no conoció prácticamente casos de bigamia o sodomía, así como de iludentes o falsarios. Estos delitos, en cambio fueron muy frecuentes en los demás Tribunales.

\footnotetext{
${ }^{7}$ AHN, Inquisición, 3.721, exp. 163.

${ }^{8}$ AHN, Inquisición, 3.722, exp. 311.

${ }^{9} \mathrm{AHN}$, Inquisición, 3.723, exp. 86; 3.730, exp. 113.

${ }^{10}$ AHN, Inquisición, 3.732, exp. 257; 3.732, exp. 415; 3.732, exp. 463; 3735, exp. 403.

${ }^{11}$ AHN, Inquisición, 3.733, exp. 60.

${ }^{12}$ AHN, Inquisición, 3.727, exp. 114.

${ }^{13}$ N. Moreno Garbayo, Catálogo de Alegaciones Fiscales, cit. p. 7.

${ }^{14}$ Véase E. Gacto Fernández, “Aproximación al derecho penal de la Inquisición”, en J.A. Escudero, Perfiles Jurídicos de la Inquisición Española (Madrid, Universidad Complutense, 1989), pp. $175-195$.
} 
a) Proposiciones

Fue el delito más frecuente, tanto en el Tribunal de Mallorca como -en generalen los tribunales de los otros Reinos Hispánicos ${ }^{15}$ (Barcelona, Canarias, Cartagena de Indias, Córdoba, Madrid, Cuenca, Granada, Lima, Logroño, Llerena, México, Murcia, Santiago, Sevilla, Toledo, Valencia, Valladolid y Zaragoza) ${ }^{16}$. Las proposiciones podían ser heréticas, erróneas, revolucionarias... y, si en los siglos anteriores habían afectado más a seglares que a clérigos, durante la época dieciochesca afectaron seriamente al clero ${ }^{17}$.

En el siglo XVIII se conocen las alegaciones fiscales del proceso de fe de Fray Bartolomé Reynés, presbítero de Palma ${ }^{18}$; el de Miguel Nicolau, también presbítero de Palma, en 1750 ${ }^{19}$; el de Bernardo Salas, presbítero de Pollensa, en 1755²0; el de Luis Romano Poncer, natural de Francia, en 1758²1; el de Jaime Oliver, canónigo de la Catedral, en $1765^{22}$; de Fray Vicente Pérez, religioso lego trinitario, en $1794^{23}$; y el de Bernardo Fiol, practicante de medicina, en $1799^{24}$.

Ya en el XIX se custodian las alegaciones de los procesos de fe de Jaime Lladó, Sargento de Artillería, por proposiciones revolucionarias ${ }^{25}$; Pedro Moll, soldado del Regimiento de Infantería de Borbón ${ }^{26}$; Juan Rosselló, presbítero de Palma, en 1801²7,

\footnotetext{
${ }^{15}$ A partir de la doctrina moralista, J. A. Alejandre y M. J. Torquemada definen el delito de proposiciones como "aquellas expresiones proferidas por algún cristiano, en las que se reflejaban puntos de vista contrarios a los artículos de fe que constituían la esencia de la Religión católica, a los mandamientos generales de la Iglesia o a las enseñanzas contenidas en las Sagradas Escrituras". Véase Palabra de Hereje: La Inquisición de Sevilla ante el delito de Proposiciones, Sevilla, Universidad de Sevilla, 1998, pp. 15-16.

${ }^{16}$ N. Moreno Garbayo, Catálogo de Alegaciones Fiscales, cit., pp. 344-346.

${ }^{17}$ Sobre las estadísticas de este delito en el Tribunal de Mallorca, véase L. Muntaner i Mariano, "Los grandes ciclos de actividad de la Inquisición española en Mallorca (1488-1691)" en Perfiles Jurídicos de la Inquisición Española, cit., pp. 753-772.

${ }^{18}$ AHN, Inquisición, 3.727, exp. 115.

${ }^{19} \mathrm{AHN}$, Inquisición, 3.732, exp. 252.

${ }^{20} \mathrm{AHN}$, Inquisición, 3.732, exp. 251, f. 1 y 2. Profirió proposiciones heréticas y renegó de Cristo, aunque al parecer había cometido "algunos excesos" y había tomado vino.

${ }^{21}$ AHN, Inquisición, 3.732, exp. 253.

${ }^{22}$ AHN, Inquisición, 3.732, exp. 236.

${ }^{23}$ AHN, Inquisición, 3.725, exp. 96, f. 2. Tenía ideas heréticas acerca de la confesión y otros sacramentos y mandatos. Creía "que el modo de confesarse es confesarse solo con Dios quien no obliga a los hombres a que manifiesten a otros hombres sus secretos..." y que "las acciones prohibidas en el sexto precepto no eran pecado, ni aun la fornicación no siendo adulterio".

${ }^{24}$ AHN, Inquisición, 3.727, exp. 116.

${ }^{25}$ AHN, Inquisición, 3.723, exp. 96. El reo tenía ideas bonapartistas y anticlericales. Sobre el carácter político del Tribunal de la Inquisición, véase J. A. Alejandre y M. J. Torquemada, Palabra de Hereje: La Inquisición de Sevilla ante el delito de Proposiciones, cit., p. 123.

${ }^{26} \mathrm{AHN}$, Inquisición, 3.723, exp. 100, f. 1 dijo que "se hacía la puñeta del predicador", "que la Virgen Santa era una puta" y que "si el daban la comunión en quaresma echaría la hostia al común". (Se trata de una traducción literal de "lloc comú", en referencia al inodoro).

${ }^{27} \mathrm{AHN}$, Inquisición, 3.722, exp. 201.
} 
Juan Montaner, escribano de la intendencia de Mallorca, en 180328; Fray Juan Rebare, en 1806 ${ }^{29}$; José Gara, chocolatero de Palma, en 1814 30 ; Marcos Tur, labrador de Ibiza, en $1814^{31}$; José Ribas, presbítero de Ibiza en el mismo año ${ }^{32}$; José Sales, presbítero de Palma, en 181433; Sor Francisca Ana Mage, originaria de Palma, en 18144; Sor Catalina Bisquerra, también originaria de Palma, en el mismo año ${ }^{35}$, Sor María Teresa Sard, palmesana, también en el mismo año ${ }^{36}$; Lorenzo Sabater, presbítero de Palma, en $1815^{37}$; y el de Manuel Rodríguez, cirujano de Mahón, en $1817^{38}$.

Destaca sobre todo, la proliferación de alegaciones de los años 1814-1817, es decir, desde la restauración de la Inquisición (con el absolutismo) hasta 1817, que es la fecha límite de esta subserie. Sin duda, en estos momentos la Inquisición actuó como tribunal al servicio de la monarquía absoluta de Fernando VII ${ }^{39}$.

Llama la atención que la mayoría de los procesados fueran eclesiásticos, entre los que destacan los procesos a tres religiosas del mismo convento, por "desprecio de los sacramentos", por contar al confesor lo primero que les venía a la cabeza y por creer que la Misa era un juego de niños, según ellas mismas decían en el locutorio conventual ${ }^{40}$. Las tres religiosas relataron que entraron en el convento siendo unas niñas y que todos los temas de religión les traían sin cuidado ${ }^{41}$.

${ }^{28}$ AHN, Inquisición, 3.727, exp. 121.

${ }^{29}$ AHN, Inquisición, 3.727, exp. 114, f. 1, no guardaba los ayunos y las penitencias, se burlaba de la confesión y de la comunión y decía "al infierno va toda gente joven y divertida, y alli me harán capitan por las cosas que he hecho aqui".

${ }^{30} \mathrm{AHN}$, Inquisición, 3.723, exp. 104, por defender la necesidad de que el Rey se sometiese a la Constitución.

${ }^{31}$ AHN, Inquisición, 3.723, exp. 97, por querer alistarse en el “gremio de los francmasones”. Véase J.A. Ferrer Benimeli, "El discurso masónico y la Inquisición en el paso del siglo XVIII al XIX, Revista de la Inquisición 7 (1998), pp. 269-282.

${ }^{32}$ AHN, Inquisición, 3.723, exp. 98.

${ }^{33}$ AHN, Inquisición, 3.721, exp. 190, f. 1, se dice que "había entrado nueve veces por el terrado en el convento acompañado de Molinas, del P. Rosselló y del medico Oliver, en cuyas ocasiones llevaba Molinas hostias consagradas y las repartia a los referidos, a esta delatora, y a las religiosas Enseñat y Fullana para que cada uno se las aplicase a las partes ocultas y de este modo cometian actos carnales".

${ }^{34}$ AHN, Inquisición, 3.721, exp. 187.

${ }^{35} \mathrm{AHN}$, Inquisición, 3.721, exp. 189.

${ }^{36}$ AHN, Inquisición, 3.723, exp. 101.

${ }^{37}$ AHN, Inquisición, 3.723, exp. 108, por no creer en Jesucristo y considerar que el Viejo y el Nuevo Testamento eran una fábula y por no creer lo que enseñaba la Iglesia.

${ }^{38} \mathrm{AHN}$, Inquisición, 3.723, exp. 105, f. 1, "por hablar mal de los sacerdotes, religiosos y obispo, tener entendido que tenía libros prohibidos y haberle oído que el titulo de cirujano era mas sagrado que el de Papa y el de Obispo".

${ }^{39}$ Véase F. Tomás y Valiente, Gobierno e Instituciones en la España del Antiguo Régimen, Madrid, Alianza, 1982, pp. 16 y ss.

${ }^{40}$ AHN, Inquisición, 3.721, exp. 187, f. 1.

${ }^{41}$ M. H. Sánchez Ortega, La mujer y la sexualidad en el Antiguo Régimen, Madrid, Akal, 1992, p. 115. 
b) Solicitación

Era el delito eclesiástico por excelencia ${ }^{42}$, cuya represión fue en incremento durante el siglo XVIII ${ }^{43}$, por lo que se conservan numerosas alegaciones fiscales ${ }^{44}$. Los diferentes tribunales de la Inquisición iniciaron los trámites para conocer este delito en un número muy elevado de religiosos. Como las denuncias eran anónimas, en muchos casos se trataba de una venganza o una traición. Hay una concentración de los delitos en Artá en un primer momento, por una denuncia que debió de tener carácter colectivo.

Se custodia la alegación de los procesos de fe de Fray Sebastián Sard, originario de Artá, en 175445; Juan Melis, presbítero, también en Artá en 175446; Fray Pablo de Mallorca, también originario de Artá, en 1759; Fray Nicolás Carbonell, en 1761 ${ }^{47}$; Miguel Pons, presbítero de Binissalem, en 177048; Fray Martín Obrador ${ }^{49}$, originario de Palma, en 1773; Fray Guillermo Lladó, en 178750; Fray Lorenzo de Mallorca, en $1788^{51}$; José Febrer, presbítero de Menorca, en $1789^{52}$; Bartolomé Tur Calafat ${ }^{53}$, presbítero de Ibiza, en 1792; Pedro Lluch, presbítero de Manacor, en 180054; P. José Mariano Telladas, en 180355; Fray Nicolás de Mallorca, en 180556; Fray Fidel de Mallorca, en 181457; José Molinas ${ }^{58}$, presbítero de Palma, en 1814; Guillermo Font, presbítero de Palma, en 1814 ${ }^{59}$; y el de Bartolomé Tomás, presbítero de Lluchmayor, en $1815^{60}$.

\footnotetext{
${ }^{42}$ Véase J. A. Alejandre, "El delito de solicitación en confesión" en S. Muñoz Machado (ed.), Los Grandes Procesos de la Historia de España, Barcelona, Crítica, 2002, cap. VIII y J. R. González Marmolejo, Sexo y confesión, México, Plaza y Valdés, 2002, pp. 25 y ss.

${ }^{43}$ Sobre las estadísticas del delito de solicitación, véase G. Dufour, Clero y sexto mandamiento: la confesión en España en el siglo XVII, Valladolid, Ámbito, 1996, p. 97.

${ }^{44}$ Véase N. Moreno Garbayo, Catálogo de Alegaciones Fiscales, cit. pp. 346-347.

${ }^{45} \mathrm{AHN}$, Inquisición, 3.732, exp. 241.

${ }^{46} \mathrm{AHN}$, Inquisición, 3.732, exp. 248.

${ }^{47} \mathrm{AHN}$, Inquisición, 3.732, exp. 237.

${ }^{48} \mathrm{AHN}$, Inquisición, 3.725, exp. 99.

${ }^{49}$ Preguntóle el religioso a una doncella de veintitrés años si "tenía pelos en las partes y si le picaban" y si tenía la regla. Vid. AHN, Inquisición, 3.732, exp. 255, f. 1. Véase el comentario de G. Dufour, Clero y sexto mandamiento: la confesión en España en el siglo XVII, cit., p. 127.

${ }^{50} \mathrm{AHN}$, Inquisición, 3.727, exp. 117.

${ }^{51} \mathrm{AHN}$, Inquisición, 3.725, exp. 101.

${ }^{52}$ AHN, Inquisición, 3.725, exp. 97.

${ }^{53}$ AHN, Inquisición, 3.725, exp. 98, f. 1 y 2. El sacerdote "le tocaba la cara con la mano y la pasó por la rejilla del confesionario".

${ }^{54} \mathrm{AHN}$, Inquisición, 3.725, exp. 100, f. 1. "Preguntó en qué disposición tenia las partes naturales y si tenia mucho pelo y otras cosas indecentes".

${ }^{55} \mathrm{AHN}$, Inquisición, 3.727, exp. 113.

${ }^{56} \mathrm{AHN}$, Inquisición, 3.727, exp. 122.

${ }^{57}$ AHN, Inquisición, 3.720, exp. 14.

${ }^{58}$ Molinas fue acusado de sacrílego y solicitante por una religiosa profesa del coro de la Misericordia. El canónigo le había enseñado el modo de invocar al demonio. AHN, Inquisición, 3.721, exp. 201. Véase G. Dufour, Clero y sexto mandamiento: la confesión en España en el siglo XVII, cit., p. 150.

${ }^{59} \mathrm{AHN}$, Inquisición, 3.723, exp. 103, por decir palabras cariñosas en la confesión.

${ }^{60} \mathrm{AHN}$, Inquisición, 3.723, exp. 107.
} 
Los procesos de fe se reparten, casi a partes iguales, entre el clero regular y el secular. Entre los clérigos regulares destaca la presencia de varios capuchinos (Fray Pablo de Mallorca, Fray Nicolás Carbonell, Fray Lorenzo de Mallorca, Fray Nicolás de Mallorca y Fray Fidel de Mallorca), aunque las alegaciones no dan pie a entender por qué hubo tantas acusaciones ${ }^{61}$. Fray Guillermo Lledó era agustino, Fray Martín Obrador era mínimo, Fray Sebastián Sard era observante y el P. José Mariano Telladas era teatino.

A tenor de lo expuesto en las alegaciones, en la mayoría de casos las víctimas eran mujeres de entre veinte y cuarenta años, entre las que abundaban las doncellas y las viudas, que tenían una posición más libre de cargas conyugales, pero que no gozaban de una protección marital. En cuanto a su distribución geográfica, puede decirse que se repartía a partes casi iguales entre la Ciudad y la Part Forana.

c) Delitos de herejía contra la religión católica

Aparecen varios delitos ligados a la religión. En cuanto a las alegaciones conservadas, se desprende de ellas un descenso respecto de otras épocas. En las alegaciones de los Tribunales de la Inquisición en los Reinos Hispánicos apenas se registraron unos sesenta casos de apostasía o renegación, unos cuarenta de masonería, unos veinte de mahometismo, unos diez de luteranismo y unos pocos más de calvinismo, protestantismo, jansenismo, arrianismo ${ }^{62} \ldots$

En otros Tribunales se establecieron procesos por molinosismo (sobre todo en Sevilla) y por judaísmo. Las tendencias molinosistas ${ }^{63}$, presentes en Mallorca durante el XVII y parte del XVIII, no fueron objeto de alegaciones fiscales. En cuanto al judaísmo, la represión había sido tan dura hasta finales del XVII, que no se iniciaron nuevos procesos durante la segunda mitad del XVIII y principios del XIX.

Se conservan las alegaciones de los proceso de fe de Juan de Serra, tratante de Palma, por apostasía, en 1723; Luis Black, natural de Inglaterra, por haberse hecho protestante y haber dejado la religión católica, de $1735^{64}$; Pedro Soulier, natural de Francia, por haberse hecho protestante, de 1756; y, por último, el de Antonio Horrach, jornalero de Santa Margarita, por renegado, en $1761^{65}$.

El más antiguo e interesante es Luis Black, nacido en Inglaterra, hijo de padres anglicanos, que había vivido en Menorca y en Marsella por temas comerciales y que decía haber estudiado Filosofía y Teología católica en Flandes con maestros católicos.

${ }^{61}$ J.A. Llorente, Historia crítica de la Inquisición de España, Barcelona, Imprenta de Oliva, 1836, tomo V, p. 117 destaca que la solicitación era más frecuente entre carmelitas descalzos, alcantaristas y capuchinos.

${ }^{62}$ Véase N. Moreno Garbayo, Catálogo de Alegaciones Fiscales, cit., que documenta unos sesenta casos de apostasía o renegación, unos diez de luteranismo y unos veinte de mahometismo, pp. 341-344.

${ }^{63}$ Véase S. Trias Mercant, Història del pensament a Mallorca, I, Palma, Moll, 1985, pp. 172-181.

${ }^{64}$ AHN, Inquisición, 3.732, exp. 249.

${ }^{65}$ AHN, Inquisición, 3.732, exp. 240. 
Al volver a Mahón educó a sus hijos en el anglicanismo, pese a declararse "católico en el fondo de su corazón". Puesto que quería pasar de Mallorca a Francia, abjuró ante el Tribunal de sus pasados errores ${ }^{66}$.

\section{d) Supersticiones, maleficios y sortilegios}

Se trata de un conjunto de delitos vinculados a la magia ${ }^{67}$, generalmente femeni$\operatorname{nos}^{68}$ y emparentados con la brujería ${ }^{69}$. En el Tribunal de Mallorca hubo la misma proporción que en el resto de los Reinos Hispánicos ${ }^{70}$. Se custodian las alegaciones de los procesos de fe de José Cerdá, pelaire de Pollensa, en 1766, por curaciones supersticiosas ${ }^{71}$; Micaela Riera Carratela, de Mahón, en 1816 $6^{72}$; Francisca Terrasa, de Petra, en $1816^{73}$; y Pedro Mayol Cardaix, labrador de Petra, en el mismo año ${ }^{74}$. En cuanto a los maleficios, se custodian la alegación del proceso de fe de Magdalena Desideri, originaria de Alcudia, en $1778^{75}$; y la del proceso que siguió Antonia Mañana, de Mahón, de $1816^{76}$. Se conservan asimismo las alegaciones del proceso de fe por sortilegios de Isabel Sala, tratante, natural de Palma, en $1772^{77}$.

e) Retención o venta de libros prohibidos

Delito frecuente, sobre todo durante las sucesivas publicaciones de los índices. A medida que las ideas liberales tomaron fuerza, tales prohibiciones fueron vulneradas con mayor frecuencia ${ }^{78}$. Se conservan las alegaciones del proceso de fe de Antonio Moll, tratante de Alcudia, en $1767^{79}$; el de Bernardo Fiol, practicante de medicina, en $1799^{80}$ (por expender libros y también encausado por proposiciones), el de José

\footnotetext{
${ }^{66} \mathrm{AHN}$, Inquisición, 3.732, exp. 249, ff. 1 y 2.

${ }^{67}$ En un sentido general, J. M. García Marín, "Magia e Inquisición: derecho penal y proceso inquisitorial en el siglo XVII", en Perfiles Jurídicos de la Inquisición Española, cit., pp. 205-275.

${ }^{68}$ Véase M. H. Sánchez Ortega, La mujer y la sexualidad en el Antiguo Régimen, cit., p. 207.

${ }^{69}$ M. J. Torquemada Sánchez, La Inquisición y el diablo. Supersticiones en el siglo XVIII, Sevilla, Universidad de Sevilla, 2000, p. 34 y ss.

${ }^{70}$ Véase N. Moreno Garbayo, Catálogo de Alegaciones Fiscales, cit., pp. 342-323.

${ }^{71} \mathrm{AHN}$, Inquisición, 3.732, exp. 244.

${ }^{72} \mathrm{AHN}$, Inquisición, 3.732, exp. 258.

${ }^{73} \mathrm{AHN}$, Inquisición, 3.723, exp. 106.

${ }^{74}$ AHN, Inquisición, 3.723, exp. 109.

${ }^{75}$ AHN, Inquisición, 3.732, exp. 256. En él deponen cuarenta y tres testigos por delitos de maleficios, sortilegios y hechicería.

${ }^{76} \mathrm{AHN}$, Inquisición, 3.723, exp. 186, que está relacionado directamente con el proceso de Micaela Riera Carratela.

${ }^{77}$ AHN, Inquisición, 3.725, exp. 95.

${ }^{78}$ Véase N. Moreno Garbayo, Catálogo de Alegaciones Fiscales, cit., que documenta un centenar de alegaciones fiscales de procesos de fe por libros prohibidos, p. 344.

${ }^{79}$ AHN, Inquisición, 3.732, exp. 238.

${ }^{80} \mathrm{AHN}$, Inquisición, 3.727, exp. 116, por poseer el libro Le Compere Mathieu, prohibido desde 1804. Véase Index Librorum Prohibitorum, Roma, Camerae Apostolicae, 1819, p. 72.
} 
de Jáudenes, intendente del Ejército, de Palma, en $1802^{81}$; y el de Guillermo Lladó, hornero de Palma, en $1814^{82}$.

f) Blasfemias

Delito contra la fe muy frecuente, sobre todo en las clases populares, tal y como ocurre en los casos que se citan a continuación ${ }^{83}$. En el Tribunal de Mallorca se examinaron un número similar al del resto de España. Se conservan las alegaciones del proceso de fe de Jaume Vanrell, alias Jaumoy, marinero de Palma, en el siglo XVIII ${ }^{84}$; el de Tomás Talladas, labrador de Campos, en $1763^{85}$; y el de Pedro Moll, soldado del Regimiento de Infantería de Borbón ${ }^{86}$ (también procesado por proposiciones, como se ha visto antes).

\section{g) Retención de figuras obscenas}

Se trata de un delito poco corriente en los primeros siglos de actividad inquisitorial y que cobró mucha relevancia en la revolución cultural de la Ilustración ${ }^{87}$. Se conservan las alegaciones del proceso de fe de de Juan Cuñil, practicante de notario en Palma, por retención y manifestación de pinturas obscenas en $1807^{88}$ y el de Bernardo Caimari ${ }^{89}$, practicante de cirugía de Palma, en $1817^{90}$.

h) Otros delitos generales

Existen también alegaciones fiscales de procesos de fe de otros temas comunes en los diferentes Tribunales inquisitoriales, aunque no muy practicados. Se encausó en 1750 a Miguel Calvo, natural de Muro, por decir misa sin estar ordenado ${ }^{91}$; Juan Despuig fue procesado en 1755 por cómplice en la poligamia ${ }^{92}$ de Francisca

\footnotetext{
${ }^{81} \mathrm{AHN}$, Inquisición, 3.727, exp. 119, por poseer un libro de Maquiavelo.

${ }^{82}$ AHN, Inquisición, 3.723, exp. 99. Lladó le enseñó a Gabriel Rivas, chocolatero, un ejemplar que tenía de "el pacto social de Rusó" y le dijo que quien quisiera verlo debía pagar una onza de oro. Presenció dicha conversación el hijo del sacristán de las monjas del Olivar.

${ }^{83}$ Véase N. Moreno Garbayo, Catálogo de Alegaciones Fiscales, cit., que documenta unos ciento setenta y cinco casos de blasfemia, pp. 341-342.

${ }^{84}$ AHN, Inquisición, 3.727, exp. 118, "por decir que la Virgen era una Puta, que San Josef es un cabro, todos los santos son unos borrachos y otras expresiones semejantes".

${ }^{85} \mathrm{AHN}$, Inquisición, 3.727, exp. 243.

${ }^{86} \mathrm{AHN}$, Inquisición, 3.723, exp. 100.

${ }^{87}$ E. Gacto, “Arte vigilado (sobre la censura estética de la Inquisición española en el siglo XVIII), Revista de la Inquisición, 9 (2000), p. 10.

${ }^{88} \mathrm{AHN}$, Inquisición, 3.727, exp. 119.

${ }^{89}$ Sobre este caso, en el que el encausado mostró diferentes pinturas que representaban a un hombre y a una mujer "en acto venéreo", véase E. Gacto, "Arte vigilado (sobre la censura estética de la Inquisición española en el siglo XVIII), cit. pp. 28-29 y C. de la Peña Velasco, En torno al Barroco: Miradas múltiples, Murcia, Editum, 2006, p. 175.

${ }^{90}$ AHN, Inquisición, 3.727, exp. 123.

${ }^{91}$ AHN, Inquisición, 3.733, exp. 60.

${ }^{92}$ Extraña la falta de alegaciones por el delito de bigamia, cuando en los otros Tribunales eran muy frecuentes. N. Moreno Garbayo, Catálogo de Alegaciones Fiscales, que documenta más de 300 casos, p. 341.
} 
Palou ${ }^{93}$; los religiosos palmesanos Fray Francisco Gómiz y Fray José Prats fueron encausados por fracción de sigilo ${ }^{94}$; Jaime Planells, capitán de Ibiza, fue procesado en 1761 por honor de oficio ${ }^{95}$; Antonio Serra y Sard, de Palma, fue encausado en 1815 por usar las insignias de familiar del Santo Oficio sin serlo ${ }^{96}$; y, por último, Fray Andrés Mas, presbítero de Palma, fue procesado por contravenir a lo prevenido en un edicto en el año $1789^{97}$.

\section{i) Otros delitos de carácter local}

Carácter específico revisten tres alegaciones fiscales de delitos que están ligados a la historia moderna de Mallorca. Dos de ellos están directamente vinculados al lulismo ${ }^{98}$ y específicamente a la confrontación entre los dominicos y todo el clero secular y regular por la negativa de los Predicadores a asistir a un Te Deum que debía celebrarse en la Catedral en honor de Ramon Llull en $1750^{99}$. Las consecuencias de esos hechos afectaron a la convivencia de los dominicos con las otras órdenes y con los poderes eclesiástico y civil.

En concreto, hubo a partir de 1750 numerosas vindicaciones por parte de los lulistas que fueron contestadas por los antilulistas fieles a la escuela dominicana y así empezaron luchas banderizas que duraron hasta el final del episcopado de Juan Díaz de la Guerra ${ }^{100}$. En este contexto, de pasquines y libelos, se incardina la alegación del proceso de fe de Juan Mayol, estudiante de Cánones y de Martín Roger, estudiante de Filosofía, que fueron procesados por haber elaborado un jeroglífico denigrativo de la religión dominicana y de Santo Tomás ${ }^{101}$.

\footnotetext{
${ }^{93}$ AHN, Inquisición, 3.732, exp. 247. Juan Despuig era el vicario general de la Diócesis de Mallorca y se le acusó de no haber sido diligente al haber bendecido la unión de Francisca Palou, cuando ésta ya estaba casada, aunque decía que era viuda.

${ }^{94} \mathrm{AHN}$, Inquisición, 3.732, exp. 254. Por fracción de sigilo de dos religiosos trinitarios. Sobre este delito y para su calificación moral, F. Echarri, Directorio moral, Madrid, Imp. de la Real Gaceta, 1779, pp. 256 ss. ${ }_{95} \mathrm{AHN}$, Inquisición, 3.732, exp. 239.

${ }^{96} \mathrm{AHN}$, Inquisición, 3.723, exp. 145.

${ }^{97}$ AHN, Inquisición, 3.725, exp. 94. El reo era un carmelita que había citado en un sermón un libro prohibido en un edicto de 1789 .

${ }^{98}$ L. Pérez Martínez, "Lulismo e inquisición a principios del siglo XVII", en J. A. Escudero (ed.), Perfiles jurídicos de la Inquisición española, Madrid, Universidad Complutense, 1989, pp. 727-752, indica que la Inquisición no se inmiscuyó nunca en asuntos lulianos durante el siglo XVI por la protección específica de Felipe II al Beato Ramon Llull. Los conflictos de la Inquisición con el lulismo (que abarcan diversos tribunales) son materia del siglo XVII. En el Tribunal de Mallorca persistieron algunos conflictos hasta la segunda mitad del XVIII.

${ }^{99}$ Véase L. Pérez Martínez, "Un nuevo texto acerca de un atentado contra el culto de Ramón Llull", Bolletí de la Societat Arqueologica Lul-liana, 41 (1985), pp. y R. Ramis Barceló, "Pasquines de lulistas y antilulistas en 1750: (Biblioteca Pública de Palma, ms. 1146)", Bolletí de la Societat Arqueolòica Lul.liana, 65 (2009), pp. 285-300.

${ }^{100}$ Sobre este asunto, R. Ramis Barceló, "El lul·lisme i l'antilul·lisme dels juristes mallorquins en els segles XVII i XVII", Studia Lulliana 50 (2010), pp. 73-95.

${ }^{101}$ AHN, Inquisición, 3.736, exp. 124, f. 3 "las figuras de abajo significaban al Dr. Roca, al demonio y
} 
En ese mismo contexto debe entenderse la alegación fiscal del proceso de fe que en 1754 se hizo a Fray Buenaventura Guasp, capuchino originario de Palma, por injurias a la religión de Santo Domingo ${ }^{102}$. Toda la Orden Franciscana, representada en Mallorca por los observantes y los capuchinos, se sintió muy agraviada por la actitud de los dominicos frente a Ramon Llull. La situación, lejos de calmarse mediante el paso de las décadas, fue agravándose, hasta el punto que en las primeras décadas del XIX fueron necesarios intentos de conciliación entre ambas órdenes mendicantes ${ }^{103}$.

El tercer caso es la alegación fiscal, ya en el XIX, del proceso de fe de Salvador Pomar, Gabriel Miró y José Bonnín, plateros de Palma, por haber rasgado un sambenito que estaba en el claustro de los dominicos ${ }^{104}$. Se trata de la evocación de una herida que retrotraía a otros momentos tristemente célebres de la Inquisición mallorquina: los procesos por judaísmo, fundamentalmente en el XVI y XVII, celebrados contra los descendientes de los judeoconversos, los llamados xuetes ${ }^{105}$.

Uno de los momentos culminantes de esta represión antijudía fueron los autos de fe de finales del XVII ${ }^{106}$, descritos con toda crueldad y lujo de detalles por el jesuita catalán Francisco Garau (de quien se hablará seguidamente). En el siglo XIX, con una Inquisición ya menguante y decadente, no es de extrañar que estos descendientes y familiares de los represaliados quisiesen rasgar el sambenito del convento de Santo Domingo, que recordaba su condición de xuetes y los mantenía en un lugar marginado en la sociedad.

al prior Cleda, porque eran contrarias a la Concepción, que el buey representaba a un dominico sin distinción por el mismo motivo: que los que suvian las escaleras eran de San Francisco y los Jesuitas por haber sido favorables, como S. Buenaventura, el B. Raymundo, Escoto y el P. Suarez, queriendo todos estos manifestar su alegría hacían aquella fiesta al modo que son las de toros poniéndose contra del buey, y que no podian acudir los dominicos que estaban al caerse por ser opuestos...". Véase también L. Pérez Martínez, "Inquisición, pasquines, lulistas y antilulistas", Mayurqa 22 (1989), pp. 873-884. ${ }^{102}$ AHN, Inquisición, 3.723, exp. 102, f. 1, el problema venía por un sermón pronunciado por un dominico en el que condenaba, siguiendo a Santo Tomás, la Inmaculada Concepción de la Virgen María, mientras que Duns Escoto y Ramon Llull la defendían.

${ }^{103}$ Algunas noticias sobre esta cuestión pueden verse en R. Ramis Barceló, "En torno a la supresión del connotativo «luliana» de la denominación histórica de la Universidad de Mallorca", Memòries de la Reial Academia mallorquina d'Estudis Genealògics, Heràldics i Històrics, 21 (2011), pp. 103-119.

${ }^{104} \mathrm{AHN}$, Inquisición, 3.723, exp. 102.

${ }^{105}$ La bibliografía es inmensa, véase el clásico B. Braunstein, The chuetas of Majorca: conversos and the Inquisition of Majorca, New York, 1936; L. Pérez Martínez, Reivindicación de los judios mallorquines: documentos para su estudio, Palma, Fontes Rerum Balearium, 1983, y de nuevo M. Colom, La Inquisició a Mallorca, cit., passim.

${ }^{106}$ Los últimos procesos de fe a judaizantes en toda España se sitúan en la década de 1720, por lo que quedan ya fuera de la subserie de alegaciones fiscales. Véase B. Bennasar, Inquisición española: poder político y control social, Barcelona, Crítica, 1981, p. 333. Al entender de L. Muntaner, los autos de fe de Mallorca se situaron en el marco de una oleada generalizada de procesos a judaizantes, por lo que el elemento económico o antisemita no debe considerarse tan decisivo como suponen autores como, por ejemplo, Braunstein. Véase L. Muntaner i Mariano, "Los grandes ciclos de actividad de la Inquisición española en Mallorca (1488-1691)" en Perfiles Jurídicos de la Inquisición Española, cit., pp. 771-772. 


\subsection{Pleitos y problemas de competencias}

En relación con las alegaciones fiscales de procesos de fe provenientes del Tribunal de la Inquisición de Mallorca, hay que decir que los pleitos y problemas de competencias con los otros Tribunales representan un total de diez casos, entre los que hay siete referentes a competencias y tres a casos civiles. Desde el siglo XVII, los problemas de competencias entre el Tribunal de la Inquisición de Mallorca y los demás tribunales revisten gran importancia ${ }^{107}$.

a) Pleitos de competencia

En la subserie se encuentran las alegaciones del pleito de competencias con la Audiencia por querer nombrar curador para los bienes secuestrados de la herencia de José Santacilia, en $1775^{108}$; del pleito de competencias con el Juzgado de Intendencia de Mallorca por los bienes de Miguel Juan Dezcallar, en 1781 ${ }^{109}$; la del pleito de competencias sobre los procedimientos del presidente de la Junta de caudales comunes contra don José Campins, portero del Tribunal, en $1793^{110}$; la del pleito de competencias con el Juzgado de la intendencia de Mallorca, por la prisión de don Nadal Espinosa $^{111}$, abogado y consultor del Santo Oficio, en 1796 ${ }^{112}$; la del pleito de competencias formado por el Tribunal a instancia de Bartolomé Serra Bennasar ${ }^{113}$, al intendente de propios de la provincia, en $1800^{114}$; y, por último, la del pleito de competencia con la Audiencia, por la causa del familiar Sebastián Selba (¿Salvá?), preso en Lluchmayor, en 1805.

b) Pleitos civiles

Se custodian las alegaciones fiscales de tres pleitos civiles, todos ellos ocurridos en el siglo XVIII. Una es la alegación fiscal del pleito de Juan Despuig Dameto, conde de Montenegro, contra Catalina Ana Forteza por los bienes secuestrados de Francisco Ferrá $^{115}$. Otro es el pleito por pretensión de Ana Pol, esposa del Dr. Juan Bautista Roca y Mora ${ }^{116}$, abogado del Real Fisco, contra Bartolomé Juliá, presbítero, por la

\footnotetext{
${ }^{107}$ Véase A. Planas Rosselló, La Real Audiencia en Mallorca en la época de los Austrias (1571-1715) Barcelona, Universitat Pompeu Fabra, 2010, pp. 109 y ss.

${ }^{108}$ AHN, Inquisición, 3.732, exp. 260.

${ }^{109} \mathrm{AHN}$, Inquisición, 3.725, exp. 102.

${ }^{110} \mathrm{AHN}$, Inquisición, 3.732, exp. 264.

${ }^{111}$ Sobre el personaje, véase A. Planas Rosselló, "Los juristas mallorquines del siglo XVIII”, Memòries de la Reial Acadèmia Mallorquina d'Estudis Genealògics, Heràldics i Històrics, 12 (2002), p. 66.

${ }^{112}$ AHN, Inquisición, 3.725, exp. 103.

${ }^{113}$ Sobre el personaje, véase A. Planas Rosselló y R. Ramis Barceló, La Facultad de Leyes y Cánones de la Universidad Luliana y Literaria de Mallorca, Madrid, Carlos III, 2011, p. 170.

${ }^{114}$ AHN, Inquisición, 3.727, exp. 124.

${ }^{115}$ AHN, Inquisición, 3.732, exp. 260.

${ }^{116}$ Sobre el personaje y su familia, véase A. Planas Rosselló, "Los juristas mallorquines del siglo XVIII", pp. 82-83.
} 
edificación de la pared de un predio, en $1759^{117}$. Por último, se encuentra la alegación del pleito sobre el recurso interpuesto por Nicolás Orlandis ante la audiencia sobre el concurso de acreedores de Francisco Ballester ${ }^{118}$.

\subsection{Informaciones genealógicas}

Se encuentran cuatro alegaciones fiscales de informaciones genealógicas para pretendientes a cargos del Santo Oficio. Se conservan la de Tomás Dusacil, natural de Palma, que pretendía el cargo de ministro oficial del Santo Oficio en $1790^{119}$; la de Catalina Ana Carbonell, natural también de Palma, para esposa del ministro oficial del Santo Oficio; la de Coloma Cirer y Cerdá, mujer de Manuel Cleto de Santiago ${ }^{120}$; y la de Ildefonso Téllez Roncalí, natural de Palma, capitán de Infantería, para secretario del Tribunal de Mallorca ${ }^{121}$.

\subsection{Calificaciones y censuras de libros}

Hay dos alegaciones fiscales de censura de libros. Una es la prohibición de un libro manuscrito titulado Examen crítico, histórico y demostrativo de los autores que negaron a María Santísima la gracia en su primer instante, de Guillermo Vidal ${ }^{122}$. El otro es más importante. Se trata de la alegación fiscal del pleito de competencia y la calificación del célebre libro La fe triunfante ${ }^{123}$ de Francisco Garau, de la Compañía de Jesús ${ }^{124}$. Se imprimió el libro con licencia del Regente y del Vicario General y se puso en venta. Posteriormente, la Real Audiencia publicó un decreto en virtud del cual se mandó al Regente retirar todos los libros y quemarlos, menospreciando así al Tribunal. El Inquisidor Fiscal alegó que se reimprimiesen ${ }^{125}$.

\section{Conclusiones}

El examen de esta subserie de alegaciones fiscales permite conocer las causas que examinó el Tribunal de la Inquisición de Mallorca durante la segunda mitad del siglo

\footnotetext{
${ }^{117}$ AHN, Inquisición, 3.732, exp. 261.

${ }^{118}$ AHN, Inquisición, 3.740, exp. 64.

${ }^{119} \mathrm{AHN}$, Inquisición, 3.725, exp. 105.

${ }^{120} \mathrm{AHN}$, Inquisición, 3.772, exp. 266.

${ }^{121}$ AHN, Inquisición, 3.772, exp. 267.

${ }^{122}$ AHN, Inquisición, 3.772, exp. 262. Nuevamente un problema referente a la Inmaculada Concepción de la Virgen María: el autor del libro defendía expresamente las posturas antitomistas e injuriosas contra la religión dominicana.

${ }^{123}$ F. Garau, La fee trivnfante en qvatro avtos celebrados en Mallorca por el Santo Oficio Mallorca, 1691. ${ }^{124} \mathrm{AHN}$, Inquisición, 3.772, exp. 263.

${ }^{125}$ Es un caso embrollado, aunque acorde con la tónica de enfrentamientos entre la Real Audiencia y la Inquisición. Véase de nuevo, A. Planas Rosselló, La Real Audiencia en Mallorca en la época de los Austrias (1571-1715), ibidem.
} 
XVIII y durante las dos primeras décadas del siglo XIX. Resulta útil examinar estas alegaciones, pues no es un período especialmente estudiado de la historia del Santo Oficio en Mallorca, y permite aventurar una serie de conclusiones generales sobre el declinar del Tribunal de la Inquisición en la isla.

En primer lugar, el Tribunal presentó una actividad ligeramente menos intensa que la de los demás Tribunales españoles. También si se compara la importante acción que había desarrollado en los siglos anteriores, puede decirse que las causas de la segunda mitad del XVIII y del XIX apenas tuvieron relevancia y siguieron la tónica de la larga decadencia inquisitorial.

En segundo lugar, muy pocos son los procesos de fe o de competencias que se sustanciaron en la Suprema y de los que se tienen conocimiento. En general, estas acusaciones no tuvieron consecuencias graves y la Suprema en pocos casos entró a fondo en los problemas. Da la impresión de que el Tribunal se ocupó en la segunda mitad del XVIII de delitos relacionados con religiosos, pero que el control social e ideológico se le escapaba de las manos. Como subraya el profesor Enrique Gacto, a finales del siglo XVIII "el Santo Oficio conocería aún nuevos períodos de auge en su actividad censoria a lo largo de los años venideros, pero sus actuaciones iban a quedar condicionadas en adelante a los intereses políticos ${ }^{126 "}$.

Efectivamente, parece que el Tribunal en el XIX fue un vestigio sólo al servicio de los intereses monárquicos y absolutistas. Llama la atención la gran actividad en 1814, momento de restablecimiento del Santo Oficio en España. Sin embargo, como ocurrió en casi todos los Tribunales, se trataba de un mero espejismo, pues ya la sociedad posterior a la Constitución gaditana no podía vivir más con la asfixia inquisitorial.

En tercer lugar, al igual que en el resto de España, de acuerdo con las alegaciones fiscales conservadas, los delitos de fe más habituales en el Tribunal de Mallorca fueron los de proposiciones y de solicitación. Durante el XVIII las proposiciones solían asemejarse a las blasfemias, mientras que durante el XIX tenían un contenido más político. Los demás delitos, salvo el de bigamia, se mantenían en la tónica de los demás tribunales.

Por último, cabe referirse a la especificidad de los conflictos locales, en los que la Inquisición llegó a tomar parte. Quedan reminiscencias de la durísima represión contra los judaizantes de Mallorca y de los disturbios entre lulistas y antilulistas, que dieron lugar a algunas alegaciones fiscales. Las procedentes de pleitos civiles y de competencias, información genealógica y calificación y censura (salvo el caso, tal vez, del libro de Francisco Garau) tienen menor relevancia. Hay que decir, en fin, que este escrito puede ser un paso más para conocer mejor la última época del Tribunal de la Inquisición en Mallorca y que facilita nuevas investigaciones sobre estos temas.

${ }^{126}$ E. Gacto, "Arte vigilado (sobre la censura estética de la Inquisición española en el siglo XVIII)", cit., pp. 46-47. 